\title{
The End of the Beginning: Society of Surgical Oncology 2013 Presidential Address
}

\author{
Monica Morrow, MD \\ Breast Service, Department of Surgery, Memorial Sloan-Kettering Cancer Center, New York, NY
}

\begin{abstract}
In September 2011, the Society of Surgical Oncology (SSO) Executive Council voted to transition to self-management. The transition was successfully completed in October 2012. This article summarizes the infrastructure changes that have occurred to facilitate the transition, the SSO goals, selected results from the 2012 Membership Survey, and future directions for the SSO.
\end{abstract}

It has been my particular privilege to serve as your president during a time of great transformation for the Society of Surgical Oncology (SSO). It has been a tumultuous and exciting 1.5 years since September 2011 when the Executive Council, meeting in emergency session, unanimously voted to transition to self-management. This article will briefly review how this decision came about within the context of the history of the SSO; discuss what has been accomplished to date thanks to the work of many SSO members, the SSO staff, and particularly Executive Director Eileen Widmer; and address some of the challenges remaining to secure our future as the premier organization for advancing the science and practice of surgical oncology worldwide.

\section{THE ROAD TO SELF-MANAGEMENT}

Like most changes, what might seem to have been a sudden event was actually the culmination of a series of events. Much of the SSO as we know it today came about after a retreat organized by then-president-elect Charles Balch in 1991 at a time when membership was declining and we had very little money. The strategic plan developed

(C) Society of Surgical Oncology 2014

First Received: 8 February 2014;

Published Online: 7 March 2014

M. Morrow, MD

e-mail: morrowm@mskcc.org at the retreat, key elements of which are summarized in Table 1, led to a period of growth and prosperity, and, in many ways, the following years were halcyon days for the SSO.

As a result, a new strategic plan was not developed until 2006, under the leadership of Raphael Pollack, MD. This resulted in a bylaws revision in 2007 to create a community surgeons committee and an international surgeons committee, with Executive Council seats for the committee chairs. As a natural outgrowth of this philosophy of greater inclusiveness, in 2008 the bylaws were again revised, eliminating surgical oncology fellowship training and publications as membership requirements and allowing physicians and scientists with "a major professional interest and commitment to oncology" to become active SSO members. In the following years, membership increased steadily, the SSO Fellowship programs thrived, and the Society's reserve funds also grew.

In 2009, after years of effort by many individuals, the American Board of Surgery approved the SSO's proposal for subspecialty certification in advanced surgical oncology. The massive amount of work to achieve this milestone was beautifully summarized by Fabrizio Michelassi in his presidential address in 2010, and Fabrizio, Ron Wiegel, and Suzanne Klimberg led this effort on behalf of the SSO. ${ }^{1}$ However, the work was far from done with the approval, and Russ Berman has been instrumental in helping to make certification the reality that it is today. As of February 2013, graduates of 8 surgical oncology training programs were approved to take the board examination.

Ironically, achieving our goal of subspecialty certification prompted another round of soul-searching regarding the SSO's mission and our ability to achieve that mission, because the relevance of a general surgical oncology society in the era of super specialization was increasingly called into question. To address these issues, President Mitch Posner began an in-depth strategic planning process that included a member survey to determine what members really wanted from the SSO. 
TABLE 1 Key elements of the 1991 SSO strategic plan

Expansion of the Nominating Committee
Creation of elected Councilor-at-Large position for member
$\leq 45$ years of age
Creation of the Corporate Relations Committee
Development of a reserve fund
New management company
Decision to create an SSO journal

The results of the 2010 member survey can be broadly summarized as demonstrating that members prioritized the annual meeting and opportunities for continuing medical education (CME) first, followed by training of surgical oncology and breast fellows, representation of surgical oncology as a discipline, and the Annals of Surgical Oncology subscription (Table 2). Miscellaneous other resources, such as grants and the Web site, received the lowest priority. The Annals performance exceeded expectations. The annual meeting and fellowship training were rated as good, but with room for improvement, whereas the SSO's activities representing the profession of surgical oncology were not felt to be quite up to snuff ${ }^{2}$.

Armed with this information, we had another strategic planning retreat. We adopted a new mission statement"Improving patient care by advancing the science and practice of surgical oncology worldwide" - and we adopted a series of values related to professionalism, quality, lifelong learning, leadership, and discovery. When we developed the strategic plan, we created a series of action items for its implementation and prioritized these initiatives. Our top administrative priorities included a complete bylaws revision and a 3-year financial plan. In education, the top priorities were the development of a method of ongoing member-needs assessment to drive programs and services and the creation of disease site task forces. We also prioritized promotion of clinical trials participation and revitalization of the James Ewing Foundation as the fundraising organization for the SSO.

What we were really attempting to do was to change the culture of the SSO from that of a society that put on an annual meeting and provided oversight for fellowship programs to a modern, full-service surgical oncology organization that addressed a spectrum of member needs. It rapidly became apparent that we had an insufficient number of staff to achieve our goals; our budget structure did not support programmatic development, and we had an excess of funds in reserve; our technology infrastructure was woefully out of date; and SSO leadership and volunteers were going to need to devote considerably more time and energy to SSO activities than attending 2 committee meetings per year to make this all happen.
TABLE 2 SSO member expectations and SSO performance 2010

\begin{tabular}{lll}
\hline Priority & Activity & Grade \\
\hline 1 & Annual Meeting + CME & B \\
2 & Training of Fellows & B + \\
3 & Professional society representation & C \\
4 & Annals of Surgical Oncology subscription & A+ \\
5 & $\begin{array}{l}\text { Resources such as research grants, Web site, } \\
\text { newsletters, and professional networking }\end{array}$ & B \\
&
\end{tabular}

I was appointed chair of an Operations Assessment Task Force by 2011-2012 President Jim Economou, and after an evaluation by external consultants, on September 23, 2011, the Task Force brought to the Executive Council a recommendation that the SSO move to self-management and develop a transition plan. This was unanimously approved. The Council also voted that the position of executive director be offered to Eileen Widmer and that a transition team consisting of me and Drs. Posner, Coit, and Charles Balch be created.

Why start over again after all our successes instead of attempting to remake the SSO within its existing management structure? As Albert Einstein said, "Insanity is doing the same thing over and over again expecting different results."

\section{WHAT DOES THE TRANSITION MEAN FOR THE MEMBERSHIP?}

The transition itself was an enormous amount of work. If we had actually had any idea of the magnitude of the job, we might never have opted to move to self-management, and certainly not within the very aggressive time frame we chose. Our management contract with EAI officially ended on October 5, 2012. The Executive Council budgeted $\$ 500,000$ for the transition, and it was completed on time and under budget, thanks to the dedication of the members of the Transition Committee, who were joined by Jeff Drebin when I became president, as well as Eileen Widmer and Cathy Bell. The most visible results of the transition are the new SSO office space and new staff. SSO headquarters opened on October 1, 2012, and is now conveniently located near O'Hare airport in space that was built for our needs. The new office space required a technology redo, and we received invaluable help in developing a plan that minimized hardware and maintenance costs when the American Society of Clinical Oncology (ASCO) generously allowed their full-time information technology director, Bernie Khoo, to work with us as a consultant.

One of the great opportunities that the transition offered was the ability to align our staffing model and the skill set 
of our employees with our committee structure and functionality. This change was essential to the future success of the SSO. We have hired a core staff (Fig. 1, shown in blue) to handle functions that are already fully developed and have moved to the use of outside contractors (shown in green) for areas where we do not currently have the workload to justify full-time employees. This combination has afforded us access to a much higher level of specialized expertise than we had with our EAI staffing model while helping to keep costs down, and the expectation is that as the Society continues to grow, some of the contracted positions will become full-time.

\section{UPDATING THE SSO INFRASTRUCTURE}

There were also a considerable number of changes to the infrastructure of the SSO even as the transition was taking place. The bylaws have been completely overhauled to remove operational details so that minor changes, such as the number of individuals on a committee, no longer require a full year to enact. Much of the information about how the Society functions has been compiled in a Policies and Procedures Manual, available on the Web site, which includes everything from how the Executive Council should conduct business to our financial policies and how our relationships with industry are governed. This document greatly enhances the transparency of the Society.

Transparency has been a long-time issue for the SSO. In the comments of both the 2010 and the 2012 surveys, a vocal minority of individuals expressed concerns that the SSO was a closed club. The Executive Council has responded to this concern, and a considerable amount of my time in the past 2 years has been devoted to creating a more inclusive, transparent, and defined infrastructure for the Society, as well as one that functions more efficiently to perform its work.

The SSO committees are the lifeblood of the Society. Over time, the committee structure had evolved into chaos as committees were added but never retired, terms of service varied from committee to committee, and some committees had no actual charges. In addition, there was not always effective communication between the Executive Council and committee leadership, resulting in committees duplicating each other's work or heading off in directions not consistent with Executive Council goals. Creating a rational, functioning committee structure became a priority, which began with an idea from Jim Economou that committees with related functions should be organized into

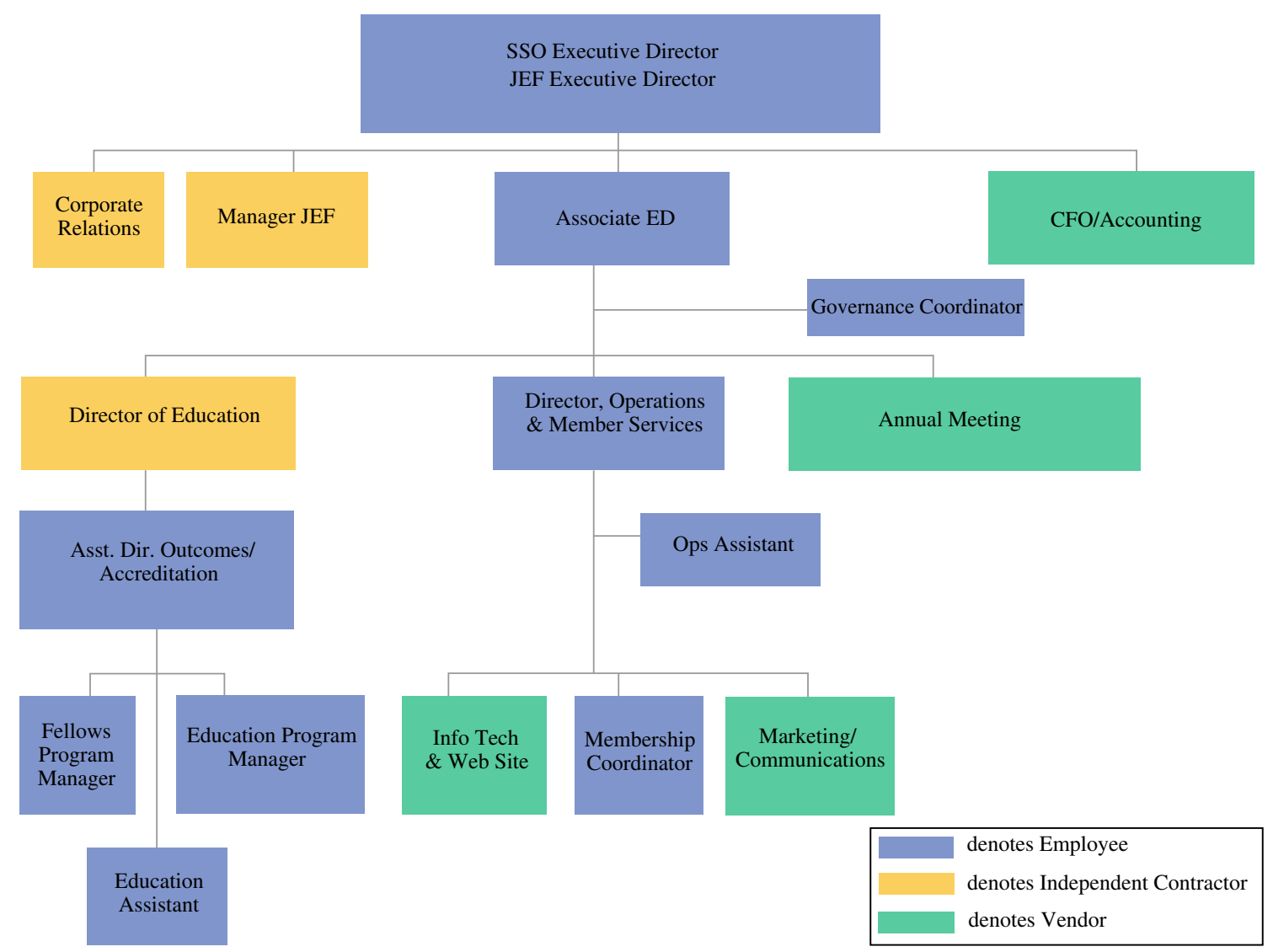

FIG. 1 SSO headquarters organization chart 
groups related to administration, education, and member services. I then undertook a review of the 29 existing SSO committees and made the somewhat arbitrary decision that after 11 consecutive years on the Executive Council, those committees whose functions I could not identify would be eliminated. The remaining committees and the newly created disease-site working groups were reorganized by council member $\mathrm{H}$. Richard Alexander, and this reorganization is summarized in Fig. 2. After reviewing of this structure and examining of our strategic plan, it became apparent that 2 new committees were needed. The Technology and Communications Committee replaced the Web site committee with an expanded charge to examine how we can use technology to enhance both communication with members and the services we provide. The Educational Products Committee was created to assess opportunities for CME, Maintenance of Certification (MOC), and enduring educational materials.

After creation of the committee structure, a handbook specifying each committee's function and defining committee processes was developed. All committee terms were standardized to 3 years, tenure for committee chairs was defined as 2 years, and a vice chair was appointed to all committees to enhance continuity. Most importantly, each committee was provided with a liaison from the Executive Council and given a series of charges for 2012, with the plan that these charges will be updated annually by the incoming president, This handbook is also available on our Web site, and I would encourage anyone on a committee, or anyone interested in being on a committee, to read it.

In an effort to increase the diversity of our committees and our Executive Council, we started at the top, with the committee that shapes the future of our society-the Nominating Committee. The Nominating Committee is charged with nominating officers and members of the
Executive Council. This committee was composed of the 3 immediate past presidents, the senior councilor-at-large, and 1 other member of the Executive Council. A bylaws amendment enacted at the 2013 Business Meeting will result in the election of 3 nominating committee members from the membership at large. One of these seats will be reserved for a community surgeon and one for an international surgeon, and one will be undesignated. Nominations will be solicited from the membership, and information about level of interest, background, and skill set will be obtained from each potential candidate. The nominating committee will provide a slate of 2 candidates for each position, as is currently done for the councilor-atlarge, to be elected by the membership. Additionally, the Executive Council seats for a community surgeon and an international surgeon will be elected by the membership as part of this amendment. In aggregate, this process will result in a leadership group that better represents the composition of the SSO, and this more diverse Executive Council will be better able to provide input to the president-elect on potential committee members.

In another move to recognize individuals from a variety of backgrounds and their contributions to the SSO, the Heritage Award has been redesignated the Distinguished Service Award. To date, the Heritage Award was given by the past president finishing his or her term on the Executive Council to a past president of his choice for contributions to the SSO. Aside from the very practical fact that we were running out of living past presidents, the Council unanimously felt that being the SSO president was ample recognition and that this award provided an opportunity to recognize other SSO members for their contributions to surgical oncology through service to the SSO, research, clinical care, or health policy. All SSO members are eligible, nominees will be chosen by the nominating

FIG. 2 SSO committee structure

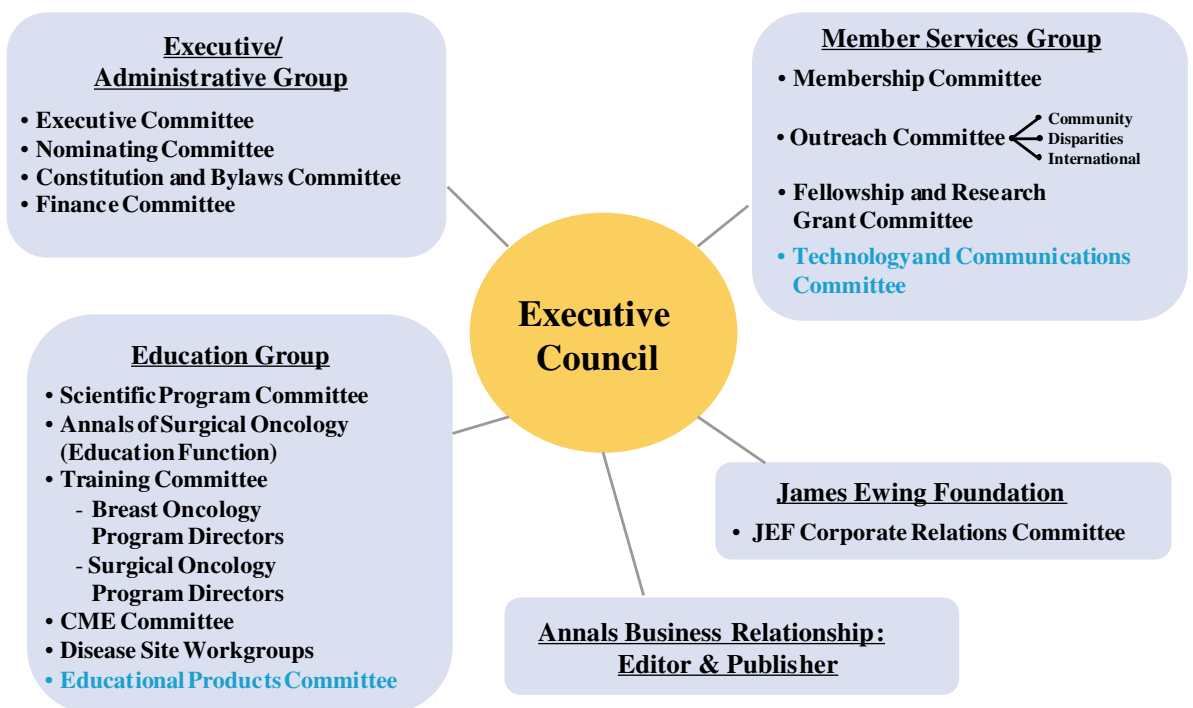


committee, and the awardee is selected by Executive Council vote. Although the 2013 honoree, Dr. David Winchester Sr., is a past SSO president, he is receiving the award for his contribution to improving the quality of cancer care through his work with the Commission on Cancer of the American College of Surgeons. The changes I have outlined in leadership selection and recognition constitute a substantial change in the way our Society has functioned to date and are needed steps if we are to maximize the use of the wide array of talent our Society has to offer and to ensure that we are not an "old boys' club."

I have highlighted only a few of the changes that have occurred in the past year, but I hope that it is apparent that even as the actual transition was taking place, efforts were well under way to respond to member concerns. Before I go on to discuss the challenges of the future and how we propose to address them, I would like to pause to acknowledge a few of the individuals who have helped to make all this progress possible. First, thanks to past presidents Mitch Posner and Jim Economou, who recognized the need for change and took the initial steps to make it happen. Overcoming the inertia of rest is always the greatest challenge. Thanks to the transition committee, Dan Coit, Mitch Posner, Jeff Drebin, and Charles Balch, for their incredible amount of work, and especially to Charles, who contracted $50 \%$ of his time and all of his management expertise to us for 12 months. I would also like to thank our entire SSO staff, who jumped right into our new enterprise with energy and enthusiasm and kept us moving forward.

We owe a real debt to Eileen Widmer, our executive director, who has served as the sole repository of the SSO's corporate memory during the transition, and who, when faced with a truly monstrous task, came through with flying colors.

\section{THE FUTURE}

So, what is next? We have taken some important steps, but a number of challenges remain, and how we address these will ultimately determine our success or failure. The most critical question is: how do we define our identity as an organization? Let me use data from the 2012 member survey to illustrate why this question is particularly relevant. We are a diverse group: $26 \%$ of our members have been in practice for more than 20 years, whereas $19 \%$ are in their first 5 years of practice. Sixty-four percent of our members are in academic practice, and $31 \%$ are in private practice; $39 \%$ designate themselves as general surgical oncologists, treating 3 or more organ sites, whereas the remainder are organ-site specialized, with breast being the most common organ site (Fig. 3).

About $70 \%$ of survey respondents felt that most or all of their expectations for a society meeting were met by the Annual Cancer Symposium, with a significant minority (30\%) expressing dissatisfaction. If we look at why people attend the SSO meeting, presentation of the latest clinical and translational science was overwhelmingly the top reason, cited by $83 \%$, followed by an overview of multiple areas in surgical oncology (70 \%; Fig. 4). In spite of this, just over half $(58 \%)$ of the respondents routinely attend the James Ewing and John Wayne lectures, although these lectures recognize major achievements in cancer care and research.
FIG. 3 SSO 2012 Membership Survey

\section{My practice is best characterized as:}

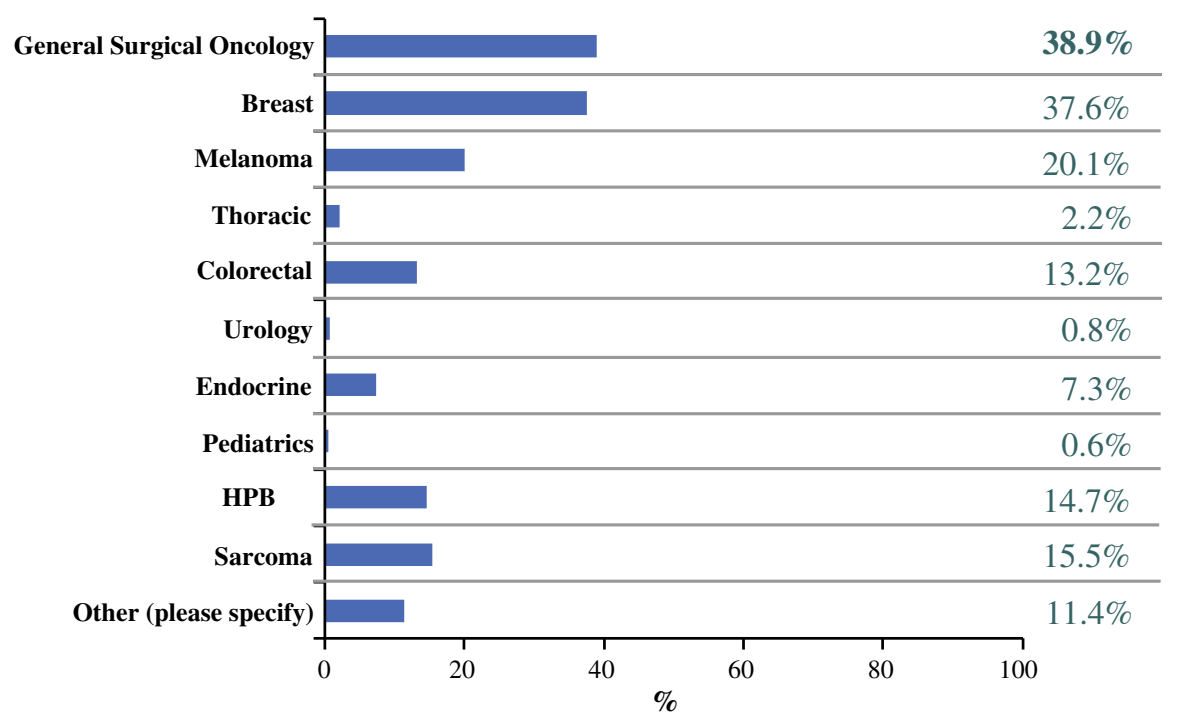

Response Percent

$38.9 \%$ . 
FIG. 4 Reasons I attend the SSO meeting

\section{Somewhat + Most Important}

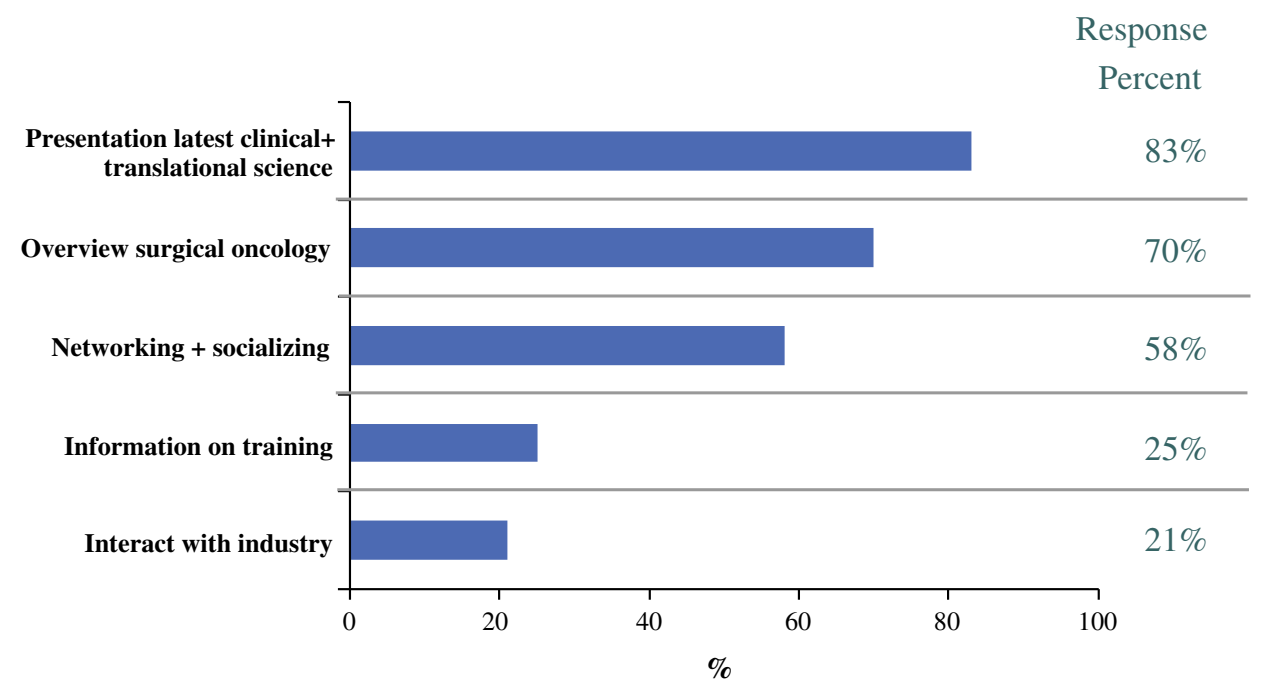

TABLE 3 Which of the following would be the most valuable enhancement to membership (somewhat or most valuable)?

\begin{tabular}{llll}
\hline General surgical oncologists & Disease-site specialists & \\
\hline Video procedure library & $72 \%$ & MOC credit & $68 \%$ \\
Patient information & $68 \%$ & Virtual meeting & $65 \%$ \\
MOC credit & $67 \%$ & Video procedure library & $52 \%$ \\
Virtual meeting & $66 \%$ & CME, MOC, OR log & $47 \%$ \\
CME, MOC, OR log & $55 \%$ & Online tumor boards & $38 \%$ \\
Online tumor boards & $52 \%$ & Patient information & $37 \%$
\end{tabular}

It is interesting that there was very little variation in response based on number of years in practice or academic versus private practice. Bigger differences were noted between general surgical oncologists and those who identified themselves as disease-site specialists. General surgical oncologists were fairly evenly divided between academic and community practice, with $42 \%$ in community practice and $54 \%$ in an academic setting. In contrast, private practitioners made up only $26 \%$ of the disease-site specialty group, with $70 \%$ of specialists in academic practice. Seventy-six percent of general surgical oncologists were satisfied with the meeting, compared with $66 \%$ of those who identified themselves as specialists. Both groups' top reason for attending the meeting was to hear presentation of the latest science.

We asked what would be the most valuable enhancement to society membership. Overall, MOC credit based on SSO material was the most highly rated, followed by access to a virtual annual meeting. A video library of surgical procedures and surgical oncology patient education materials were also highly rated, whereas there was less enthusiasm for an online log to track CME, MOC, and operative cases and for interactive, internet-based tumor boards. Breaking this down by general surgical oncologists versus specialists, there again were some differences, but the enhancements rated most highly by both groups were the ability to get MOC credit at the SSO meeting and access to a virtual meeting (Table 3). I am delighted to say that both of these became a reality at the 2013 meeting.

After careful consideration of how to meet the needs of this diverse group, the Executive Council believes that the identity of the SSO is defined by its ability to provide education and representation for the entire spectrum of surgical oncology. Based on input from the membership, we have identified three areas of focus to begin to increase our visibility and improve member satisfaction: improve the annual meeting; function as the "big tent resource" for surgical oncology education for multiple constituencies; and enhance our role representing surgical oncology through advocacy, position statements, and guidelines.

\section{IMPROVING THE ANNUAL MEETING}

There were many comments on the survey related to the annual meeting. These included the absence of high-quality translational and basic research on the program, concerns about the dominance of major cancer centers on the program, and a lack of understanding of the abstract-selection process. Everyone should be aware that the program committee is blinded to authors and institutions when they review abstracts.

I investigated whether abstracts from Memorial SloanKettering Cancer Center (MSKCC) and the University of Texas M. D. Anderson Cancer Center (MDACC) are 
disproportionately represented on the program. This year, 639 abstracts were submitted: $34(5 \%)$ came from MSKCC or MDACC. The acceptance rate for abstracts from these institutions was $62 \%$; the acceptance rate for all other abstracts was $69 \%$.

More importantly, we are making efforts to improve the quality of the scientific program. For the past 2 years, initial abstract review was by content experts on the program committee, followed by review of the abstracts being considered for oral presentation by members of the disease site working groups. Additionally, part of the charge to the disease site working groups annually is to identify the top three developments affecting care for their disease site and to determine whether any are appropriate for inclusion in the annual meeting program. This approach greatly increases the number of individuals who have input into the program. We have also entered into agreements with the Japanese Society of Gastrointestinal Surgeons and the European Society of Surgical Oncology to put on joint symposia in alternating years to be sure that our meeting reflects advances throughout the world.

The issue of how to incorporate more science into the SSO meeting is complex. In the 2010 survey, $81 \%$ of respondents felt there was a good balance of basic, translational, and clinical science, and $90 \%$ felt there should not be more basic science. Additionally, comments indicate that translational researchers often do not submit their best science to the SSO meeting. To begin to incorporate the best science relevant to surgeons into the annual meeting, the Executive Council made the decision to include topquality research, recently published or presented elsewhere and coauthored by an SSO member, in some parallel sessions at this year's meeting. We made this decision and then asked you what you thought about it in the survey; happily, $82 \%$ of the members favored or strongly favored this approach. The disease site working groups and Programs Committee members were asked to nominate papers; three outstanding papers were selected, and we anticipate expanding this program next year. Additionally, to attract the best science of all types, we have dropped the requirement that all oral presentations at the annual meeting must be submitted to Annals of Surgical Oncology for publication, although we continue to strongly encourage submission to the Annals.

\section{FUNCTIONING AS A RESOURCE FOR SURGICAL ONCOLOGY EDUCATION}

The Annual Meeting and the Annals of Surgical Oncology are our existing educational vehicles. The era of board certification in surgical oncology, coupled with requirements for $\mathrm{CME}$ and $\mathrm{MOC}$ to maintain general surgery certification, provided the opportunity for the SSO to expand its educational offerings for those whose primary interest is surgical oncology. The SSO's Surgical Oncology Self Assessment Program (SOSAP), a Web-based program envisioned by Suzanne Klimberg and the Education Council and developed by Ron Wiegel and a team of SSO volunteers, made its debut in the spring of 2013. This program can be used by those studying for Surgical Oncology board certification, as well as to obtain MOC credit for those recertifying in general surgery. At the 2013 meeting, we also had an "MOC Café" where immediate, on-site MOC credit could be obtained for selected educational sessions. Also, for the first time in 2013, we have a virtual meeting, available online and free of charge to attendees and available for purchase by members and nonmembers who did not attend the annual meeting. Capture of the entire meeting will also allow us to develop enduring CME materials based on these presentations over the course of the upcoming year. We are also expanding our international educational efforts through a partnership with ASCO, which takes advantage of their well-developed International Best of ASCO Program, currently licensed in 20 countries. SSO abstracts will be comarketed with ASCO abstracts to allow host countries to select a multidisciplinary program. Moving forward, the Educational Products Committee is charged with evaluating potential new educational initiatives based on their utility to the membership, cost to develop, and potential to generate revenue for the SSO.

\section{ACTING AS A VOICE FOR SURGICAL ONCOLOGY}

In many ways, the final objective of acting as a voice for surgical oncology is the most difficult to achieve. The SSO is a relatively small organization, and its financial resources are modest. However, the convergence of healthcare reform and the development of computerized learning systems means that there will be a greater demand than ever before for practice guidelines, quality standards, and evidence-based consensus statements. The development of practice guidelines that meet the Institute of Medicine's criteria for "trustworthiness" is a time-consuming and expensive process that requires a systematic review of the literature to inform the guideline as well as grading the strength of the evidence that supports each recommendation. We made our first foray into the creation of this type of guideline with the development of a joint SSO-American Society for Radiation Oncology (ASTRO) consensus on Margins in Breast-Conserving Surgery for Invasive Cancer, cochaired by myself and Meena Moran for ASTRO and funded by a grant from Susan G. Komen. ${ }^{3-5}$ In 
addition to SSO and ASTRO, the group includes representatives from the American Society of Breast Surgeons, the College of American Pathologists, ASCO, and a patient advocate. Guideline development is an area we wish to expand, but at present, the SSO budget has limited capacity to support the $\$ 20,000-\$ 35,000$ cost per guideline, so funding needs to be obtained from grants or foundations.

We are also expanding our role in quality and advocacy. In 2012 we joined an ASCO-led coalition to work to decrease oncology drug shortages. In April 2012 the Choosing Wisely Initiative released its initial lists of unnecessary tests and procedures developed by a variety of specialty organizations. The SSO was not a participant. This year, when a second round of commonly used tests not supported by evidence was solicited, SSO submitted its top 5 list, an effort coordinated by Sandra Wong.

In considering how SSO could become more actively engaged in the quality arena, it became apparent that in the short term, rather than building our own quality infrastructure, it made sense for us to partner with organizations with existing quality programs. At the Summer 2012 Executive Council Meeting, we considered the question of partnering with surgical subspecialty societies and came to the conclusion that it made more sense for us to partner with another umbrella organization to which we would bring value added, namely, ASCO. I was charged with identifying areas where closer collaboration between our organizations would be mutually beneficial and, after discussions with ASCO leadership, developed the following list of potential collaborations: best of ASCO, provision of surgical guidelines for ASCO's computerized rapid learning system, partnering in ASCOs new Quality Care Symposium, and expansion of ASCO's existing Quality Oncology Practice Initiative to surgical oncology practices. These collaborations address quality issues across the spectrum of our membership and were presented to the Executive Council for prioritization. We also plan to explore opportunities for closer collaboration with the American College of Surgeons Commission on Cancer Program as a way to reach larger constituencies with our quality initiatives.

All of the initiatives I have discussed, related to both educational products and policy, cost money. Our expanded agenda has necessitated a change in how we manage our money. The SSO previously had an operating budget and a large reserve fund, which was essentially untouchable. Programmatic items not related to the cost of staff and the Annual Meeting were infrequently proactively budgeted for and were added on throughout the year with little thought to the overall bottom line. Under the guidance of Chief Financial Officer Steve Berger, we have now moved to a much more accountable program-based budget and divided our funds into three buckets: (1) reserves, equal to
1.0-1.5 times the annual operating costs, untouchable except in the case of catastrophe, such as cancellation of the annual meeting; (2) a much more well defined programbased annual operating budget; and (3) a research and development fund which is allocated by the Executive Council to proposed new projects on the basis of merit, with the expectation that over time, these projects will become revenue generating, or at least revenue neutral, repay the fund, and move to the Operating Budget. The first of these projects was SOSAP, which was supported with $\$ 200,000$ from this fund, which we plan to recoup from sales and industry sponsorship.

To minimize the costs of our new initiatives to SSO members, we have been working to revitalize the James Ewing Foundation (JEF), the fundraising arm of the SSO. Under the leadership of JEF President Bill Cance, the JEF has been revamped as a separate corporate entity from the SSO. Although we are committed to external fundraising, we are also attempting to increase member giving to the JEF and, as a first step, reached out to the Executive Council and the JEF Board. I am delighted to say that we achieved $100 \%$ participation from these groups, and giving to the JEF this year reached an all-time high.

The changes in our financial management were the final piece necessary to carry out the transformation of our Society. In a relatively brief period of time, we have redefined our purpose in light of the realities of today's world. We have completely reengineered the infrastructure of our Society to allow us to meet our goals. We are in the process of changing our governance to be more inclusive, and we are developing new products and services in response to member feedback so that the SSO of the future will be much more than an annual meeting and a journal. Are we finished? Can we give ourselves a big pat on the back and go home and go back to sleep? I think not. In the words of Sir Winston Churchill, speaking after the British victory at El Alamein ended a long string of defeats in the North African campaign in World War II, "Now is not the end. It is not even the beginning of the end. But it is perhaps, the end of the beginning."

I thank you again for the privilege of serving as your president. It has stretched my mind, it has alternately energized and exhausted me, and it has definitely been the highlight of my professional career.

\section{REFERENCES}

1. Michelassi F. SSO presidential address: subspecialty certificate in advanced surgical oncology. Ann Surg Oncol. 2010;17:3094-103.

2. Posner MC. It's not the destination, it's the journey": 2011 Society of Surgical Oncology presidential address. Ann Surg Oncol. 2012;19:2073-80. 
3. Moran MS, Schnitt SJ, Giuliano AE, et al. SSO-ASTRO consensus guideline on margins for breast-conserving surgery with whole breast irradiation in stage I and II invasive breast cancer. Ann Surg Oncol. 2014;21:704-16.

4. Moran MS, Schnitt SJ, Giuliano AE, et al. SSO-ASTRO consensus guideline on margins for breast-conserving surgery with whole breast irradiation in stage I and II invasive breast cancer. J Clin Oncol. 2014 (Epub ahead of print).

5. Moran MS, Schnitt SJ, Giuliano AE, et al. SSO-ASTRO consensus guideline on margins for breast-conserving surgery with whole breast irradiation in stage I and II invasive breast cancer. Int $J$ Radiat Oncol Biol Phys. 2014;88:553-64. 